\title{
Research on ecological compensation of urban residual space to promote social integration
}

\author{
Yu Chen ${ }^{1}$, Longwei Zhang ${ }^{1 *}$, Chao Wang ${ }^{1}$, Xue Ding ${ }^{1}$ \\ ${ }^{1}$ School of Architecture and Urban Design, Shenyang Jianzhu University, 110168 Shenyang, China
}

\begin{abstract}
The continuous urbanization leads to a large number of land lost farmers pouring into the city, and the social integration of these people has become an important research topic of urban renewal. By means of field exploration and in-depth visit, this paper investigates and collates the data of some typical urban residual spaces where new industrial workers live, and finds that these spaces have common spatial characteristics, such as single spatial level, poor ecological environment and lack of landscape facilities. Then, by using statistical analysis and structural model, the comparative analysis of different types of space, and finds that the use of ecological compensation regulation can form a reasonable spatial layout, high-quality ecological effects and rich service facilities, so as to improve the spatial quality of urban residual space and provide highquality space environment for new industrial workers, Promote social integration, social integration of workers in new industries.
\end{abstract}

\section{Background}

In recent years, with the rapid development of China's urbanization, the central area of the city continues to expand to the periphery of the city. Some farmers have lost the land they depend on to survive, and become "three noes" with "no land for farming, no employment, and no share of subsistence allowances" [1]. They become new industrial workers and stay in the city, hoping to integrate into the city and share resources. However, the lag of urban development does not consider the living space of this kind of people. They are trapped in the dilemma of weak information, weak development and weak resources. In order to remove the social restrictions, they stay in the public space of the city through the way of group gathering to obtain urban resources. This way of life breaks the rules of space and transforms the living and entertainment space originally provided for urban residents into the commercial gathering space mainly in the form of primitive economy - "urban residue space". This form and the life style of urban residents contradict with each other, and the activity space of urban residents is greatly limited. Common urban residual space, including passive idle corner green space, dark roadside green belt, messy space under the bridge and so on. The urban residual space studied in this paper is a dilapidated space which is gradually occupied by new industrial workers due to the lack of management and maintenance [2]. However, this does not mean that the "space monopoly" of new industrial workers should be denied, and the "space monopoly" behavior should not be solved by administrative means of simply driving them away. We should provide them with a warm city home through urban renewal. Therefore, how to intervene in this social problem and play a positive role of landscape designers is the main research content of this paper.

\section{Regional environmental characterist- ics of "urban residue space"}

\subsection{Environmental data collection of "urban resi- due space"}

A large number of new industrial workers seek new vitality in the "urban residue space", and spontaneously form a certain scale of new industrial workers cluster. From August 1 to August 31, 2020, the author conducted field survey, data sampling and in-depth interview on more than 60 "urban residue spaces" in Shenyang in three time periods (7:00-8:00, 11:00-12:00, 16:00-17:00) every day. Through the regional population structure, ecological characteristics and facilities characteristics of the information to conduct in-depth research. By means of indepth interviews, this paper summarizes the behavior characteristics and basic needs of workers and people in new industries, and lists six representative spaces.

\subsection{Analysis of environment and crowd char- acteristics of "urban residue space"}

"Urban residue space" is generally located in the old urban areas, where supporting infrastructure is scarce and landscape service facilities are backward. Compared with the urban space in the new urban area, the cost of living is lower, and it is easier to generate natural economic and commercial forms (Table 1).

\footnotetext{
* Corresponding author: z_lw@sjzu.edu.cn
} 
According to the survey results, we find that these "urban residue spaces" have the following characteristics:

1) From the perspective of spatial location, new industrial workers tend to choose the areas with high density of urban residential areas, avoid the main roads, commercial and office clusters, and choose the areas surrounded by urban secondary roads and urban branch roads. These areas have a large population base, convenient transportation, wide vision, and avoid largescale transient crowd.

2) In terms of the ecological effect of space, the greening rate of most areas is low and the spatial level is single. After the new industrial workers settle in, they spontaneously gather on the street for a long time, resulting in a single population in the space. Only a few areas with high greening rate and complete space facilities have diversified population structure.

3) In terms of space facilities, most of the areas have no space facilities, the parking of electric vehicles in the area is disorderly, and the crowd in the area has no space to block out the wind and the sun; workers in new industries are standing on the street without corresponding commercial support facilities. The interior of the venue is open, with few people and lack of entertainment and leisure facilities.

\section{Analysis on environmental suitability of "urban residual space"}

\subsection{Research assumptions}

$\mathrm{R}$ : As the main evaluation index, public space attraction includes (R1) user structure, (R2) population size, (R3) work and rest time. Q: Public space location suitability index includes (Q1) spatial location, (Q2) traffic condition, (Q3) spatial area. H: Ecological environment suitability index includes $(\mathrm{H} 1)$ greening rate, $(\mathrm{H} 2)$ green space form, (H3) arbor and shrub coverage. S: The convenience index of public space facilities includes (S1) the number of facilities and (S2) the distribution of facilities.

\subsection{Data fitting analysis}

The attraction degree of public space is an important standard to determine the quality of space. Therefore, this element is used as a reference condition and is fitted with other relevant factors to find the following characteristics (Figure 1).

Table1. Spatial and crowd characteristics of "urban residue space"

\begin{tabular}{|c|c|c|c|c|c|c|}
\hline Site name & $\begin{array}{l}\text { Site area } \\
\text { (HA) }\end{array}$ & $\begin{array}{l}\text { Residential } \\
\text { density }(\%)\end{array}$ & Number of participants & $\begin{array}{l}\text { Travel } \\
\text { time }\end{array}$ & $\begin{array}{c}\text { Greening rate } \\
(\%)\end{array}$ & Space facilities \\
\hline \multirow{2}{*}{$\begin{array}{l}\text { Butterfly } \\
\text { Garden }\end{array}$} & \multirow{2}{*}{0.3} & \multirow{2}{*}{40} & New industry workers $25-30$ & 7 & \multirow{2}{*}{$20 \%$} & Chair \\
\hline & & & city dweller $15-20$ & 1 & & Pavilion \\
\hline Nameless Plaza & 0.76 & 35 & New industry worker35-50 & 6 & $10 \%$ & Nothing \\
\hline \multirow{3}{*}{$\begin{array}{l}\text { Model Worker } \\
\text { Park }\end{array}$} & \multirow{3}{*}{1.3} & \multirow{3}{*}{80} & New industry worker50-90 & 8 & \multirow{3}{*}{$70 \%$} & \multirow{3}{*}{$\begin{array}{c}\text { Chair } \\
\text { Pavilion }\end{array}$} \\
\hline & & & $\begin{array}{l}\text { Second hand peddler of urban } \\
\text { residents } 10-12\end{array}$ & 3 & & \\
\hline & & & city dweller $25-28$ & 7 & & \\
\hline \multirow{3}{*}{$\begin{array}{l}\text { Tieyou Staff } \\
\text { Square }\end{array}$} & \multirow{3}{*}{4.6} & \multirow{3}{*}{40} & New industry worker20-30 & 7 & \multirow{3}{*}{$45 \%$} & \multirow{3}{*}{ Nothing } \\
\hline & & & $\begin{array}{l}\text { Second hand peddler of urban } \\
\text { residents } 3-5\end{array}$ & 2 & & \\
\hline & & & city dweller $14-18$ & 3 & & \\
\hline \multirow{2}{*}{ Minyue Plaza } & \multirow{2}{*}{1.6} & \multirow{2}{*}{85} & New industry worker $50-80$ & 8 & \multirow{2}{*}{$60 \%$} & Chair \\
\hline & & & city dweller $24-33$ & 4 & & Sports facilities \\
\hline \multirow{2}{*}{$\begin{array}{l}\text { Shuangyong } \\
\text { Forest }\end{array}$} & \multirow{2}{*}{8} & \multirow{2}{*}{75} & New industry worker30-60 & 8 & \multirow{2}{*}{$65 \%$} & \multirow{2}{*}{ Nothing } \\
\hline & & & city dweller 20-30 & 5 & & \\
\hline
\end{tabular}

1) The location suitability of public space is the main factor affecting the attraction of public space. When the density of residential areas around the urban public space is more intensive, the number of new industrial workers is larger, and the demand of urban residents for urban public space is stronger.

2) Ecological environment suitability also significantly affects the attraction of public space. Through data analysis, it is found that the higher the greening rate, the larger the number of new industrial workers and urban residents, and the longer the activity time; the lower the greening rate, the more single the crowd structure and the shorter the activity time.
3) The convenience of public space facilities is an important factor affecting the attractiveness of public space. Diversified space facilities can attract a large number of people. In the area with poor space facilities, the structure of the crowd is single, the scale is small, and the residence time is relatively short.

\subsection{Model verification and calculation results}

Using Amos software tools to verify and modify the initial model, the relationship between the correlation degree of each element is displayed, and the correlation degree is " $\mathrm{Q}>$ $\mathrm{H}>\mathrm{S}$ ". For ordinary citizens, the degree of associ-ation is 
"Q $>\mathrm{H}>\mathrm{S}$ ". In the selection of public space, the needs of the two groups are basically the same. Therefore, high quality regional location, reasonable green layout and optimized public space facilities build a bridge between new industrial workers and urban residents.

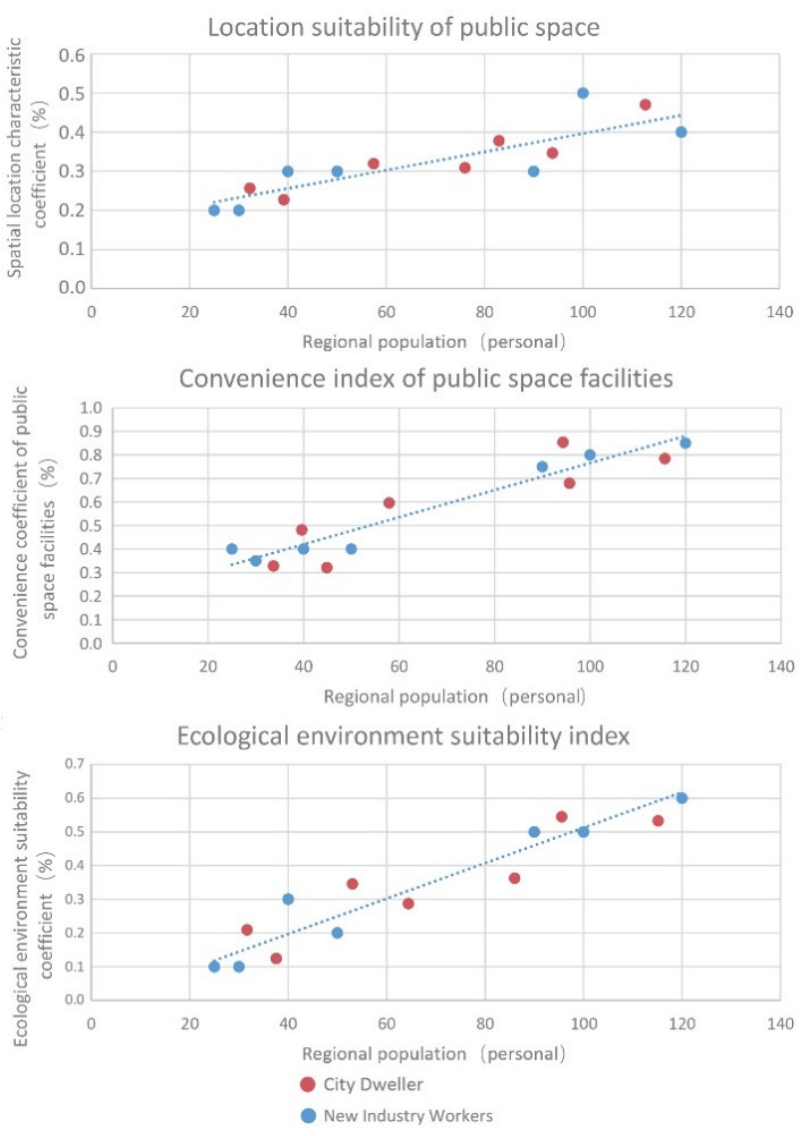

Figure 1. Fitting simulation of urban spatial attractiveness between new industrial workers and urban residents

\section{Technical strategies for ecological re- newal of "urban residue space"}

\subsection{Reorganization of ecological resources and environmental network architecture}

The main reason for the over concentration of "urban residue space" population is that the ability of new industrial workers to obtain employment information is limited. They can only form the regional identity through the agglomeration effect to form the "information source". Therefore, we should open up the exclusive space belonging to this group in the city, and distribute it in the important space nodes of the city to form a urban recruitment market space network by region, scale and level [3].

Through the way of "urban acupuncture", the "urban leftover space" and the "urban corner space" form a whole urban space network, and a large number of new industrial workers are dispersed into a number of small-scale groups, which are distributed in the urban space network. This can not only reduce the adverse impact of new industrial workers' group aggregation on urban space, but also expand the service radius of new industrial workers and provide business services for more old urban areas. Then, the urban spatial network used by new industrial workers is nested with the geographic positioning function of the Internet, so that urban residents can establish a sustainable and feedback recruitment market cluster of new industrial workers through the positioning system of travel tools, which is convenient for urban residents to locate the recruitment market of new industrial workers through travel software (Figure 2).
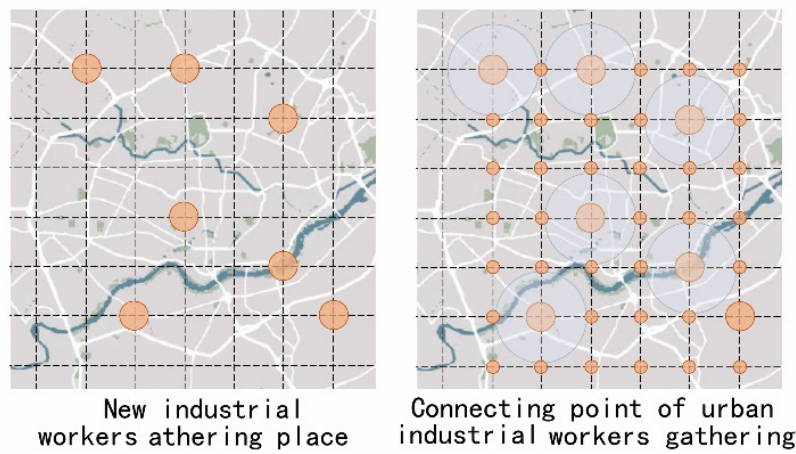

Connecting point of urban industrial workers gathering

Figure 2. Connection point setting of new industrial workers gathering

\subsection{Construction of ecological scene and cross of various activities}

The construction of ecological scene can not only reasonably plan the layout of urban residual space, but also give rich vitality to the original rigid site; improve the regional ecological effect and create environmental microclimate; create a rich scene space, enrich the forms of venues and activities, and form cross activity forms, so as to provide a strong guarantee for the social integration of new industrial workers.

1) Reasonable planning of spatial layout. The main problem of urban residual space lies in the high homogeneity of space, the lack of independent activity space for new industrial workers and urban residents. Through the intervention of green plants, the two groups of new industrial workers on the street and leisure entertainers inside the venue are created with their own independent functional areas. The long-term stable operation mode provides stable commercial value and close geographical relationship for new industrial workers. This independent consumption scene shapes a higher quality spatial level through the renewal principle of "micro intervention and microcirculation", attracts more homogeneous types of people, and enable the urban space to produce sustainable vitality [4].

2) Improve the regional ecological effect. The green space with rich layers can absorb and reflect the solar radiation and reflection function, which can better block the rapid air circulation and mitigate the adverse effects of daily temperature changes; a large amount of water absorbed by plants from the soil wetted the surrounding environment through transpiration of leaves, forming a high-quality microclimate environment. The dust caused by urban traffic can be reduced by effective canopy 
coverage; through the effective absorption and transfer of pollution particles by plant leaves, it plays the role of dust retention and dust collection; through the effective thickness of forest wind field structure, particles are prevented from entering the urban residual space. The above measures can improve the regional ecological environment and promote the sustainable development of urban residual space (Figure 3).

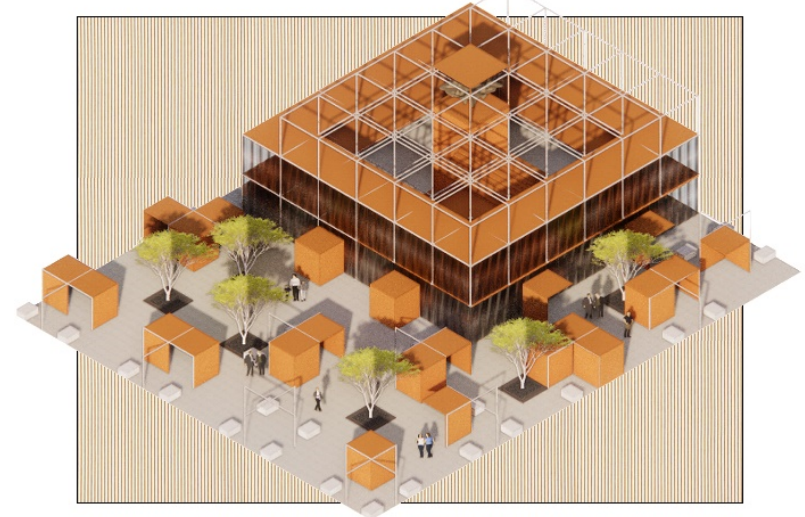

Figure 3. Landscape intention generation of embedded scene

\subsection{Building ecological module and implanting digital technology}

The main reason for the phenomenon of spatial separation is that new industrial workers have no independent spatial boundaries in urban space[5]. Therefore, it is very necessary to establish a special use space for this group. Exclusive space can not only show their professional characteristics, but also form a regional identification system, reflecting the diversified characteristics of urban landscape At the same time, it can better limit the commercial space of new industry workers and eliminate the interference to other space of the site[6]. However, the spatial forms of "urban residual space" are different, and it is impossible to complete the renovation of all spaces through a unified structure. Therefore, this paper considers introducing modular landscape structures to meet the needs of spaces with different characteristic. The "adaptive" unit framework and various activity modules are nested to form the overall "landscape module". The framework of free allocation and diversified combination form diversified landscape facilities module through unified standardized construction mode. It provides more selectivity and full adjustability for landscape facilities module, so as to adapt to different design conditions and functional requirements.

\section{Summary}

The continuous urbanization has caused a large number of new industrial workers to rush into cities. How to provide a comfortable space environment and make it better interact with urban residents has become an urgent problem in urban renewal. In this paper, a large number of "urban residual space" space problems are effectively combed, summarized and summarized. It is found that improving the ecological quality of space is an effective means to promote the interaction between new industrial workers and urban residents. This paper takes the new industrial workers as the target, ecological compensation as the means, and urban space as the medium, and puts forward the following corresponding renewal strategies: firstly, planning a reasonable urban ecological network, providing a high-quality space system for the new industrial workers, and dispersing the new industrial workers crowded in the urban core space into the "urban corner space". At the same time, we should establish a regional identification system to form an independent urban commercial space cluster belonging to new industrial workers. Secondly, through the way of ecological compensation, ecological restoration is carried out in the new industrial workers' gathering area to provide more ecological environment for "urban residue space". Through the embedding of green form, more reasonable functional zoning will be created to form the new industrial workers' commercial space, urban residents' use space and the integration and transition space of a variety of people. Finally, through the embedded multi-functional modular landscape structure, the new industrial workers' commercial landscape module, urban planting landscape module and urban residents' sports and leisure landscape module are formed, which provides various service functions for all kinds of people in the urban residual space, thus creating a strong guarantee for the social integration of new industrial workers.

\section{Acknowledgments}

The authors gratefully acknowledge the support of Scientific Research Plan of the Educational Department of Liaoning Province(Grant lnjc202003).

\section{References}

1. Huang Kaiping, Qin Zhi, Wang Li. Countermeasures for the resettlement of landless farmers in the construction of new urban areas $[\mathrm{J}]$. China market, 2020 (36): 13-15

2. Lu Luguang. From differentiation and isolation to harmonious communication: Research on urban social communication [J]. Academia, 2005 (03): 106114

3. Zhang Wenwu, Ou Xi. Agglomeration effect, congestion cost and urban spatial structure evolution [J]. Journal of Hebei University of economics and trade, 2020,41 (01): 28-38

4. Huang Lu. Thinking on urban public landscape design strategy of caring for vagrants [J]. Anhui architecture, 2017,24 (06): 8-10+82

5. Xin shanchao, Wang Zhiqiang. Speculation on the construction of modular connection -- Research on Architectural "design build" based on modular system [J]. Journal of western human settlements, 2016,31 (06): 23-28

6. Qiu Baoxing. Symbiosis and eco city [J]. Urban planning, 2013,37 (09): 9-16 + 50 